\title{
Measuring Musical Self-Regulation: Linking Processes, Skills, and Beliefs
}

\author{
Laura Ritchie $^{1,2}$ \& Aaron Williamon ${ }^{2}$ \\ ${ }^{1}$ Department of Music, University of Chichester, UK \\ ${ }^{2}$ Centre for Performance Science, Royal College of Music, UK \\ Correspondence: Laura Ritchie, Department of Music, University of Chichester, College Lane, Chichester, West \\ Sussex PO19 6PE, UK. Tel: 44-1243-816-256. E-mail: l.ritchie@chi.ac.uk
}

Received: February 2, 2013 Accepted: February 18, 2013 Available online: March 1, 2013

doi:10.11114/jets.v1i1.81 URL: http://dx.doi.org/10.11114/jets.v1i1.81

\begin{abstract}
This research explores self-regulated learning behaviors as used by 174 students in higher music education during learning and practice, with the aim of demonstrating the interaction between processes, skills, and beliefs. A three-factor structure was identified within a newly adapted, ten-item Musical Self-regulated Learning Questionnaire, illustrating (1) reflection and frameworks for progress, (2) improvement in and outside of practice, and (3) setting the learning context. The four behaviors in Factor 3 least used by these students were arranging/imagining rewards/punishments, rearranging the physical setting, keeping records of events, and reviewing records of past events/performances. Significant positive correlations were found between behaviors and self-ratings of musical skills/attributes and with self-efficacy for musical learning. However, there were no significant correlations with self-efficacy for musical performing. Students' perception of the importance of self-regulated learning behaviors, their relationships to skills and beliefs, and implications for learning and teaching are discussed.
\end{abstract}

Keywords: self-regulated learning, musical practice, self-efficacy, musical skills

\section{Introduction}

When students undertake self-regulated learning they take an active role in initiating, choosing, and carrying out the learning process, as opposed to following or reacting to external impetus or instruction. Within music this relationship between choices and processes is evidenced through students' practice. The methods used by various levels of musicians from beginners to professionals have been observed, and the importance of high quality musical practice, across the broad trajectory toward expertise, has been well documented (Ericsson, Krampe, \& Tesch-Römer, 1993; Williamon \& Valentine, 2000; Hallam 2001a; McPherson \& Renwick, 2001; McPherson \& Renwick, 2011).

McPherson and Remwick (2011) comment that there are "highly cited music studies that have dominated the literature since the 1990's" (p.338). Although there have been numerous studies exploring a student's approach to practicing, there have been few music studies that have examined the overall concept of self-regulation within music using validated questionnaires. Studies within music have built on this early research using the underlying theory as a base (McPherson \& Renwick, 2001), and others have moved away from validated questionnaires to use more qualitative methodologies (for a more comprehensive review of qualitative studies, see McPherson \& Renwick, 2011).

\subsection{Processes and Skills}

It is understood that practicing can happen both with and without the instrument, as activities such as mental rehearsal, listening, and score study also contribute to learning (Jørgensen, 2004; Clark \& Williamon, in press). Practice strategies can include a range of activities, from choosing to practice either a part or the whole of a piece (Hallam, 1997), tothe method for approaching difficult passages through segments or sections of the piece (Miklaszewski, 1989), or the use of material from studies or exercises to address technical challenges in other repertoire (Nielsen, 1999b). The strategies that students adopt will depend on their resourcefulness and capabilities for engaging with meta-cognitive strategies for practicing (Jørgensen, 2004). Without any ingenuity 
a student could repeat what a teacher instructs, in rote-type learning, and progress may be hindered by technical and other challenges - physical or mental - that accompany playing the music on their instrument.

In educational contexts, studies have dissected the application of learning behaviors in the classroom, illustrated a lack of self-regulation in less experienced learners, and shown that the use of these skills could be enhanced in more advanced students (Risemberg \& Zimmerman, 1992; Zimmerman, 2002). The self-regulated learning interview schedule was developed and validated by Zimmerman and Martinez-Pons $(1988,1990)$ when researching learning in an academic classroom environment. The interview schedule asked students about various learning behaviors, and researchers classified them according to learning contexts, such as when doing homework or in an exam situation.

McPherson and Renwick (2001) developed this research by adapting part of it to a musical setting to explore the way students used different learning contexts. They studied beginning instrumentalists' practice over a three year period. In the beginning stages of learning, student behavior lacked the complexity and resourcefulness needed to effectively direct their own learning, and they therefore often relied on teachers input in order to make progress (see also Hallam, 2001b). The learning methods used to prepare a piece for performance were the focus of the qualitative study by Nielsen (2001), which catalogued and highlighted the usefulness of strategies such as setting goals and self-monitoring as observed during practice sessions by two students in higher education.

\subsection{Self-efficacy Beliefs}

Musical learning involves a high degree of autonomy, even from the early stages of engagement. It draws upon motivation and is shaped by the way people perceive and react to their performance. These personal beliefs hold a pertinent role within the cycle of becoming a self-regulated learner, as defined by Zimmerman (2002), involving forethought, volition or 'doing', and reflection. The self-beliefs students hold about their goals have been shown to have an impact on motivation and learning strategies (Zimmerman et al., 1992; Ames \& Archer, 1998).

Self-efficacy beliefs are one element in a complex web of factors that shape the decisions people make about their pursuits, the approach and the methods used to carry out a task, and the results produced. These beliefs relate specifically to someone's capabilities to successfully carry out a criterial task (Bandura, 1977). Self-efficacy beliefs have a direct impact on attainments, and the persistence and perseverance during the process of working toward a goal or carrying out a task also vary depending on self-efficacy beliefs (Greene \& Miller, 1996; McPherson \& McCormick, 2006). Self-efficacy is pertinent to musical and everyday functioning, and people who have high self-efficacy also tend to exhibit a range of positive qualities: for example, they are more likely to choose more challenging tasks, work harder and use a wider variety of cognitive strategies, persevere longer, and attain higher outcomes (Zimmerman, 2000).

These beliefs are separate from any globalized or whole self-view, and the task specific nature of self-efficacy means that there is no one self-efficacy belief to cover all situations; a person's self-efficacy for tasks in different domains, requiring different skills, may be varied or even unrelated. Even within music there can be different types of self-efficacy for separate tasks. For example, self-efficacy for learning involves beliefs in capabilities to acquire the skills and knowledge needed to perform a task (Schunk, 1996, p.7). It also sustains motivation and leads to effective use of self-regulatory strategies (Zimmerman, 1989; Zimmerman \& Martinez-Pons, 1990; Zimmerman et al., 1992), whereas self-efficacy for performing involves beliefs about executing a task successfully by implementing an already learned set of skills (for a review, see Ritchie \& Williamon, 2011).

Students with high self-efficacy tend to set mastery, not ego-based, goals which are structured in a hierarchical system, allowing them to self-monitor their progress (Zimmerman \& Martinez-Pons, 1990, 1992; Zimmerman, 2000). These skilful learners demonstrate the highest levels of concentration, self-regulated learning, and strategy use in order to attain their goals (Nielsen, 2001; Barry \& Hallam, 2002). The positive personal qualities, such as persistence, use of varied strategic approaches, and high achievement (Bandura, 1998; Zimmerman, 2000) present in those with high self-efficacy are characteristics that also contribute to positive and effective independent learning. The postulated reciprocity between self-efficacy and self-regulated learning implies that self-regulated learning is also at least partially acting as an influence on self-efficacy beliefs, and examining self-regulated learning and its relationship to self-efficacy may allow the effect of these beliefs on behavior to be illustrated.

\subsection{Aims of the Present Study}

The present research builds on McPherson \& Renwick's research, by developing the other aspect of Zimmerman \& Martinez-Pons' validated Self-regulated Learning Interview Schedule to investigate the learning behaviors 
used by music students during learning and practice on their instruments and aims to go further by demonstrating the interaction between processes, skills and beliefs. Relationships between self-regulated learning, both as an overall concept and as discrete behaviors, are examined alongside other self-ratings of musical skills and two recently validated musical self-efficacy scales.

\section{Method}

\subsection{Respondents}

A sample of 174 undergraduate music students from across levels within the undergraduate degrees at a university and conservatoire volunteered and completed the self-regulated learning questionnaire. They were a sub-set of those reported in a validation study of the self-efficacy for musical learning and self-efficacy for musical performing scales by Ritchie and Williamon (2011) and they represented a cross section of the music students at these two institutions, enabling researchers to understand the habits and beliefs of the typical student studying here. They comprised 77 men and 97 women with ages ranging from 18 to 69 years (median=21). The students specialized in a broad range of musical instruments: voice $(n=38)$, piano $(n=33)$, strings $(n=48)$, woodwind $(n=34)$, brass $(n=15)$, and percussion $(n=6)$. The sample was composed of students from a conservatoire $(n=72)$ and a university music department $(n=102)$, and all 174 are included in the analyses below corresponding to the validation of a new musical self-regulated learning questionnaire.

Within that sample, 139 respondents completed a larger suite of questionnaires exploring the interrelationships between self-regulated learning, self-efficacy and perceived musical skills (see Procedure below). This sample comprised 62 men and 77 women with ages ranging from 18 to 67 years (median= 20). The students' specialisms were voice $(n=30)$, piano $(n=32)$, strings $(n=42)$, woodwind $(n=21)$, brass $(n=10)$, and percussion $(n=4)$, and they were approximately evenly divided between students from the conservatoire $(n=72)$ and from the university $(n=67)$.

\subsection{Materials}

The learning behaviors from the Self-regulated Learning Interview Schedule developed to examine the self-regulated learning behaviors of high school students in mathematics and English classes (Zimmerman \& Martinez-Pons, 1988), was adapted for the present research in music. When adapting the questionnaire, the introductory statement 'When practicing or learning music, how often do you:' was added to create an appropriate musical context for the ten self-regulatory behaviors that followed.

When necessary, the wording of categories was modified to become appropriate to reflect self-regulation in an explicitly musical context. For example, 'rearrange materials to improve learning' became 'change the order of passages within a piece or the inclusion of studies of other related musical material'. Students' levels of self-regulation for each behavior listed in the questionnaire were rated on a 7-point Likert-type scale, from 1 (almost never) to 7 (almost always). It was hypothesized that the scale, with its minimal modifications would transfer directly from academic contexts and that it would be possible to draw conclusions about these students' musical self-regulation.

In its original context, the self-regulated learning behaviors were not aggregated to create any composite or overall score representing the students' self-regulated learning. In this study, however, in addition to examining individual learning behaviors, the grouping of behaviors is investigated through testing the internal reliability and structure of the new questionnaire. See Appendix 1 for the complete Musical Self-regulated Learning Questionnaire.

Some students only completed the self-regulated learning questionnaire, but the majority of the participants also completed the Self-efficacy for Musical Learning and Self-efficacy for Musical Performing questionnaires Ritchie \& Williamon, 2011) and a list of musical skills and attributes (listed in Table 2). The two self-efficacy questionnaires each contain a number of questions rated on a Likert-type scale that contribute to an overall score, which ask the respondent to rate the level of confidence in capabilities in approaching and carrying out a specific task. The self-efficacy for musical learning questionnaire has a maximum score of 77 and the performing questionnaire, 63, where a high score represents a strong sense of self-efficacy for that task. The audit of musical skills and attributes was a self-audit of 21 different topics where participants rated their own level in each area by using a 7-point Likert-type scale.

\subsection{Procedure}

All respondents in the current study completed the Musical Self-regulated Learning Questionnaire. Those who did so as a part of a wider study $(n=139)$ to validate the self-efficacy questionnaires(reported in Ritchie and Williamon, 2011) completed a suite of subsequent questionnaires comprising two inventories measuring 
Self-efficacy for Musical Learning and Self-efficacy for Musical Performing as well as self-ratings of a list of musical skills and attributes. All questionnaires were either completed on paper with a researcher present or were accessed on-line.

\section{Results}

\subsection{Data Analyses}

The self-regulated learning questionnaire was tested for robustness using Cronbach (1951) alpha scores. Then, to explore the questionnaire's validity, Exploratory Factor Analysis (EFA) was employed. These data analysis procedures were carried out using all participants $(n=174)$, ensuring an adequate sample size to conduct these internal reliability and data reduction tests reliably (Nunnally, 1978). Table 1 shows the mean scores and standard deviations for the self-efficacy questionnaires, musical skills and attributes.

Table 1. Descriptive statistics for skills and attributes

\begin{tabular}{lll}
\hline Musical skills and attributes & Mean & SD \\
\hline Ability to work with others & 5.29 & 1.15 \\
Management of everyday stress & 5.64 & 1.37 \\
Stamina & 4.98 & 1.94 \\
Acute ear/ detailed listening & 4.99 & 1.25 \\
Ability to memorize & 4.67 & 1.63 \\
Ability to sight read & 4.42 & 1.78 \\
Ability to improvise & 4.05 & 1.74 \\
Quantity of practice & 4.44 & 1.44 \\
Technical proficiency & 4.90 & 1.17 \\
Quality/ effectiveness of practice & 4.89 & 1.22 \\
Quality and control of tone & 5.38 & 1.16 \\
Ability to engage in effective mental rehearsal & 4.78 & 1.45 \\
Musicality, interpretative or expressive skills & 5.42 & 1.11 \\
Sense of stylistic appropriateness & 5.26 & 1.11 \\
Ability to communicate musically with the audience & 5.32 & 1.33 \\
Ability to learn new musical material and concepts quickly and easily & 5.03 & 1.17 \\
Level of perseverance & 5.31 & 1.18 \\
Ability to manage stage fright & 4.62 & 1.69 \\
Motivation and drive to excel & 5.61 & 1.27 \\
Overall musical ability & 5.24 & 1.07 \\
Overall standard of performance & 5.13 & 1.23 \\
\hline Self-efficacy for musical learning & 61.68 & 9.42 \\
Self-efficacy for musical performing & 47.88 & 7.70 \\
\hline Mean scores and stan
\end{tabular}

Description: Mean scores and standard deviations for each of the musical skills and attributes and the Self-efficacy for Musical Learning and Self-efficacy for Musical Performing Questionnaires.

\subsection{Internal Reliability and Validity}

Across the full sample of students who completed the Musical Self-regulated Learning Questionnaire ( $n=174)$, a Cronbach alpha score of 0.71 was achieved, which is above the acceptable level to indicate that the questionnaire is internally reliable as one complete instrument. Table 1 shows that removing any individual self-regulated learning behavior from the questionnaire would not improve its overall robustness.

EFA was carried out using the Maximum-Likelihood method using Quartimax rotation, as with the validation of the self-efficacy scales reported by Ritchie and Williamon (2011) following the hypothesis of a single underlying factor (Stewart, 1981). Factors were retained using the criteria of eigenvalues that were over 1 and of factor loadings that were above 0.4 (Kaiser, 1960; Guadagnoli \& Velicer, 1988). A three-factor solution was produced, and to reinforce that the results of the factor analysis were accurate, the Varimax rotation, which is the most common rotation when a multi-factor solution is produced (e,g, see Field, 2005), was also carried out. This produced the same three-factor solution, with eigenvalues of 2.87, 1.76, and 1.08. The rotated factor loadings are provided in Table 2. 
Table 2. Cronbach $\alpha$ and Factor Loadings

\begin{tabular}{|c|c|c|c|c|}
\hline Musical self-regulated learning behavior & $\alpha$ & $\begin{array}{c}\text { Factor } \\
1\end{array}$ & $\begin{array}{c}\text { Factor } \\
2\end{array}$ & $\begin{array}{c}\text { Factor } \\
3\end{array}$ \\
\hline 1. Evaluate the quality of progress of learning. & 0.69 & 0.941 & & \\
\hline $\begin{array}{l}\text { 2. Rearrange materials to improve learning (changing the order of } \\
\text { passages within a piece or the inclusion of etudes or other related } \\
\text { musical material). }\end{array}$ & 0.68 & 0.535 & & \\
\hline $\begin{array}{l}\text { 3. Set goals and plan for the sequencing, timing, and completion of } \\
\text { activities in relation to those goals. }\end{array}$ & 0.67 & 0.423 & & \\
\hline $\begin{array}{l}\text { 4. Seek information from non-social sources (recordings, concerts, } \\
\text { books or scores). }\end{array}$ & 0.68 & & 0.883 & \\
\hline 5. Keep records of events or results. & 0.70 & & & 0.451 \\
\hline $\begin{array}{l}\text { 6. Select and rearrange the physical setting (practice environment) to } \\
\text { facilitate learning. }\end{array}$ & 0.70 & & & 0.568 \\
\hline 7. Arrange or imagine a reward/punishment for success/failure. & 0.70 & & & 0.682 \\
\hline 8. Rehearse and make an effort to memorize through practice. & 0.68 & & 0.417 & \\
\hline 9. Seek assistance from peers, teachers or others. & 0.69 & & 0.446 & \\
\hline 10. Review records of past performances or exams, notes or texts. & 0.66 & & & 0.479 \\
\hline Overall $\alpha$ and $\%$ of variation & $\alpha=0.71$ & $28.7 \%$ & $17.6 \%$ & $10.8 \%$ \\
\hline
\end{tabular}

The three-factor solution clusters the self-regulated learning behaviors around different aspects of learning. These could be interpreted as factors centered on (1) reflection and creating a framework for progress, (2) the active pursuit of improvement in and outside of practice, and (3) setting the learning context. These factors illustrate related aspects of different learning strategies as opposed to describing a single underlying behavior. As the internal reliability analysis suggests, they do all contribute to form a whole, although each individual item has merit as a self-regulated learning behavior without the support of the others. For example, a student may demonstrate aspects of self-regulated learning through actively rearranging materials to facilitate learning without also demonstrating the other behaviors. What the internal reliability test shows is that these behaviors equally contribute to the questionnaire, and that the removal of any one of them would not strengthen the questionnaire. The EFA illustrates that there are underlying relationships between the behaviors, representing separate aspects or processes involved in learning, that can form a more complete, composite picture when combined. Thus, one could use this questionnaire to examine the overall level of musical self-regulation exhibited by a musician, or one could investigate the relationships shown between factors (or individual items), depending on the aims of the study or educational initiative.

\subsection{Self-regulated Learning and Its Correlates}

A number of students $(n=35)$ did not complete the entire suite of questionnaires and could not be included in subsequent analyses; thus, all further results reported henceforth are for $n=139$, as described in Respondents above. The means and standard deviations for students' levels of self-regulation for each of the behaviors are shown in Table 3. The four behaviors in Factor 3 had the lowest mean scores, implying they were perceived as being less important for musicians than the other behaviors: arranging or imagining rewards or punishments, rearranging the physical setting, keeping records of events, and reviewing records of past events or performances.

To further understand the ways the students' self-regulated their learning, their reported levels of self-regulation were analyzed with reference to both the students' scores on two self-efficacy scales, for musical learning and for musical performing, and to a list of musical skills and attributes. These ranged from technical control and mastery of mental and physical requirements of practicing and performance to other aspects of managing the extra-musical skills such as stress and working with others. This was done in relation to the self-regulated 
learning score as a whole, to each of the three factors identified, and to the individual behaviors. The self-efficacy for musical learning scores did correlate significantly with three of the behaviors, which were also represented by one of the factors extracted in the factor analysis. However, there were no correlations with any of the aggregate self-regulated learning scores, the extrapolated factors, or the individual learning behaviors and the self-efficacy for musical performing scores. The correlation of behavior use with the skills and attributes are shown in Table 2. Correlations highlighted with the grouped behaviors, in factors, and also with the overall self-regulated learning score and skills are shown in Table 3. These correlations with skills were not subsumed by a single element of self-regulated learning, but distinct skills correlated with certain behaviors and factors, suggesting that there are specific approaches used to address different areas of musical skill. The correlations between the learning behaviors and self-efficacy for learning were only seen with Factor 1 (i.e. reflection and creating frameworks for progress, see Table 4).

Table 3. Descriptives and correlations with self-regulated learning behaviors

\begin{tabular}{|c|c|c|c|c|c|c|c|c|c|c|c|c|c|}
\hline $\begin{array}{c}\text { Self-related learning } \\
\text { behavior }\end{array}$ & $\operatorname{Mean}(S D)$ & A & $\mathrm{B}$ & $\mathrm{C}$ & $\mathrm{D}$ & $\mathrm{E}$ & $\mathrm{F}$ & G & $\mathrm{H}$ & I & $\mathrm{J}$ & $\mathrm{K}$ & $\mathrm{L}$ \\
\hline 1 & $4.73(1.52)$ & & & $.24 *$ & & & & .20 & & & & & \\
\hline 2 & $4.38(1.56)$ & & & .19 & & .22 & & & & & & & \\
\hline 3 & $4.55(1.62)$ & .18 & & $.33 *$ & & & $.38 *$ & $.26 *$ & $.36 *$ & .19 & $.31 *$ & $.35 *$ & \\
\hline 4 & $4.83(1.55)$ & & & & & & & & & & & & \\
\hline 5 & $4.03(1.94)$ & & .21 & & & & & & .22 & & & & \\
\hline 6 & 3.94(1.95) & & & .19 & & & .21 & & $.31 *$ & & & & .22 \\
\hline 7 & $3.83(1.88)$ & .23 & & $.24 *$ & & & & & $.28 *$ & .22 & & .18 & .19 \\
\hline 8 & $5.13(1.78)$ & & $.26^{*}$ & & .21 & & & & $.27 *$ & & & & .18 \\
\hline 9 & $5.57(1.22)$ & & & & & & & & & & & & \\
\hline 10 & $4.21(1.82)$ & & & & & & & & .18 & & & & \\
\hline
\end{tabular}

Note:(A) acute ear/detailed listening, (B) ability to memorize, (C) quality/effectiveness of practice, (D) sense of stylistic appropriateness, (E) ability to learn new musical material quickly and easily, (F) motivation and drive to excel, (G) ability to work with others, (H) quantity of practice, (I) technical proficiency, (J) ability to engage in effective mental rehearsal, $(\mathrm{K})$ perseverance, $(\mathrm{L})$ overall musical level.

Description: Mean scores and standard deviations for each of the ten items in the Musical Self-regulated Learning Questionnaire, as well as the Pearson correlations between self-regulated learning behaviors and musical skills and attributes $(n=139)$. All correlations $p<.05$, * indicates $p<.01$.

Table 4. Correlations between skills and aspects of self-regulation

\begin{tabular}{|c|c|c|c|c|}
\hline & & Factor 1 & Factor 2 & Factor 3 \\
\hline Musical skill or attribute & $\begin{array}{l}\text { Self-regulated } \\
\text { learning score }\end{array}$ & $\begin{array}{c}\text { Reflection/ creating } \\
\text { frameworks }\end{array}$ & $\begin{array}{c}\text { Improvement through } \\
\text { practice }\end{array}$ & $\begin{array}{l}\text { External } \\
\text { elements }\end{array}$ \\
\hline $\begin{array}{l}\text { Ability to collaborate/ work } \\
\text { with other performers }\end{array}$ & .224 & $.267^{*}$ & & \\
\hline Acute ear/detailed listening & $.236 *$ & .203 & & \\
\hline Ability to memorize & & & .195 & \\
\hline Ability to sight-read & & .197 & & \\
\hline Quantity of practice & $.389 *$ & $.256^{*}$ & $.239 *$ & $.354 *$ \\
\hline Technical proficiency & .189 & .173 & & \\
\hline $\begin{array}{l}\text { Quality/effectiveness of } \\
\text { practice }\end{array}$ & $.302 *$ & $.331 *$ & & .223 \\
\hline $\begin{array}{l}\text { Ability to engage in } \\
\text { effective mental rehearsal }\end{array}$ & .196 & .207 & & \\
\hline $\begin{array}{l}\text { Sense of stylistic } \\
\text { appropriateness }\end{array}$ & .221 & .177 & .182 & \\
\hline $\begin{array}{l}\text { Ability to communicate } \\
\text { musically with the audience }\end{array}$ & .187 & & & \\
\hline Level of perseverance & .228 & .284 & & .190 \\
\hline $\begin{array}{l}\text { Motivation and drive to } \\
\text { excel }\end{array}$ & $.264^{*}$ & $.270^{*}$ & & .205 \\
\hline
\end{tabular}


Note: For the list of behaviors in each factor, see Appendix. All correlations $p<.05$, * indicates $p<.01$.

Description: Pearson correlations between musical skills and attributes and self-regulated learning factors and the overall self-regulated learning score $(n=139)$.

Table 5. Correlations between learning behaviors and self-efficacy

\begin{tabular}{ll}
\hline \multicolumn{1}{c}{ Self-related learning behavior } & Self-efficacy for learning \\
\hline Evaluate the quality of progress of learning. & $.30^{*}$ \\
Rearrange materials to improve learning. & .17 \\
Set goals and plan for the sequencing, timing and & .18 \\
completion of activities in relation to those goals. & \\
\hline Factor 1 & $.28^{*}$
\end{tabular}

Description: Pearson correlations between self-regulated learning behaviors, individually and as factors, and self-efficacy for learning scores ( $n=139)$. All correlations $p<.05, \quad *$ indicates $p<.01$.

\section{Discussion}

The self-regulated learning questionnaire showed internal reliability; and a three-factor solution aligned individual behaviors with different aspects and process involved with learning. Each behavior on the self-regulated learning questionnaire could be examined as an individual micro-example of self-regulated learning, as the self-regulated learning behaviors each independently demonstrate self-regulated learning, although the tests performed here have illustrated that the questionnaire also demonstrates the construct with one score. Therefore, in research where this self-regulated learning questionnaire is used, either the composite score or the identified factors should be used in subsequent studies. The individual behaviors remain important for teachers and learners, as in order to improve a factor, each component behavior would need to be addressed. The three-factor solution does, however, demonstrate that self-efficacy beliefs have a home with certain areas of the self-regulation process. The behaviors relating to reflecting and creating frameworks correlated with the self-efficacy beliefs and this is consistent with self-regulation theory (Zimmerman, 2002). These beliefs are integral to decision making and choosing courses of action, within the self-regulatory cycle of evaluating and then goal setting for the next target. This factor that related to self-efficacy also represented the largest factor, being responsible for the most variance within the construct. The finding that self-efficacy related to self-regulated learning follows patterns found within other research that found intrinsic factors to be the strongest predictors of self-regulation (Renwick \& McPherson, 2009).

With the students in this study, many of the skills and attributes showed correlations across a range of the self-regulated learning behaviors, as shown in Tables 2 and 3. The diversity inherent in this sample, with small groups in some instrument families, may have influenced the range of significant correlations, and there may also be differences in approach due with studying certain instruments; for example some instruments may not traditionally make an effort to memorize music, as it may not be required. Therefore, although these initial results are representative for this sample, samples specifically focused on different levels of education, various approaches to learning within different genres of music, or specific instrumental specialisms would show trends for how different musicians use self-regulated learning behaviors across their musical development.

Zimmerman, Bandura and Martinez-Pons (1992) found the self-regulated learning behaviors in this questionnaire to be relevant in the academic setting, and although the end-product of music (i.e. performance) is obviously different to a piece of writing or to arithmetic problems, there are clear similarities in the approach and process for achieving the result. When a mathematical concept is introduced in a classroom setting, students will then repeatedly engage with the concept in various forms, either through written repetition or recitation of sums or tables, before moving on to combine that concept with more complicated elements. In music technical skills or passagework are often approached in much the same way, with the introduction of a concept and in order to ensure accuracy, the physical action required is practiced and repeated. The similarity of approach between music and academic subjects is found when new concepts are introduced and progressively built, as in mathematics and English grammar. Repetition is a tool used to aid with memorizing lists of information, for example spelling words or historical dates. The more creative elements of musical phrasing and the 
experimentation involved when creating nuance of sound are akin to the processes found in creative writing. Students will undertake several drafts and may change single words in order to communicate their point more effectively. In musical expression, dynamics might be changed, or the color of a note altered with vibrato or another effect. Although musical learning requires a specific set of skills, including highly physical elements and distinct mental understanding of concepts involving pitch and tone, musical processes are sufficiently similar to those in academic learning that these self-regulated learning behaviors also apply to musicians.

\subsection{Correlated Behaviors}

The self-regulated learning behavior of seeking assistance from others had the highest reported levels of use. This is a positive behavior that enables students to engage in modeling, listening, and critical appraisal, and also gives the opportunity for positive reinforcement of performed concepts once learning has been accomplished. As Risemberg and Zimmerman (1992) noted, even with students who are already engaging with strategies and achieving well, it is possible to improve their use of self-regulated learning behaviors. There is an opportunity to educate students about the various applications of these behaviors in different musical settings so they can explore them within their learning. An improvement in the use of self-regulated learning behaviors could bring about more correlations with both skills and with self-efficacy for learning beliefs.

There were many correlations between skills and learning behaviors on all levels of examination within the self-regulated learning questionnaire, showing a wide-ranging use of musical self-regulation in practical settings. Several of the musical skills correlated with more than one behavior or factor of behaviors, illustrating that the different musical skills and attributes could be addressed and improved through the use of a number methods of self-regulated learning, depending on the demands of the specific musical situation. Because the context of the self-regulated learning questionnaire was not restricted to specify one setting for learning, for example approaching a new piece of repertoire for the first time, it would be possible that students considered their approach to and application of self-regulated learning with regard to their current musical studies, which could range from the extremes of learning new repertoire, to working on music that was polished and ready for a performance. The implication of this is that a new distribution of correlations could arise with subsequent samples as metacognition, or the thinking about learning, is not the same at all levels of learning but is a function of expertise (Barry \& Hallam, 2002, p.154). What has been highlighted is that these music students address their skills and attributes with different self-regulated learning behaviors and that no single strategy was used for everything, see Tables 2 and 3.

The correlations between the self-efficacy for musical learning scores and both the individual self-regulated learning behaviors and their associated factor, reflection and creating frameworks for progress, and the lack of correlations with self-regulated learning behaviors the self-efficacy for performing questionnaire, on any level overall score, factor, or individual behavior - reinforces that the self-efficacy questionnaires indeed measure distinct types of self-efficacy in music. These results further support the statistical validation of these self-efficacy questionnaires carried out in Ritchie \& Williamon (2011) by providing additional evidence to support the theoretical understanding of the methods and behaviors associated with these beliefs. As with the skills and attributes, if the self-regulated learning questionnaire was also oriented to the same task as the self-efficacy for learning questionnaire, then more significant correlations representing a distinctive pattern between the behaviors and the self-efficacy for learning scores would be expected to relate to the type of learning undertaken.

\subsection{Uncorrelated Behaviors}

The self-regulated learning behaviors within factor 3, elements external to the physical act of learning music, were used less frequently by these musicians. As the self-regulated learning questionnaire was designed to assess behavior of high school students in classroom-based subjects, it is possible that the lower ratings given by the music students sampled here indicated that these particular categories of behavior were either not as important for music students, not appropriate for tertiary level students, or that these students did not know or understand their value or application and therefore did not use them as frequently. Rewards and punishments emphasize the incremental nature of goals and create a tangible framework with which a student can recognize and acknowledge achievement. This behavior could be seen as beneficial for those who may not be able to complete the learning cycle without some external motivation or assistance. The more mature students surveyed in this research may be more independent learners who do not require this additional external intervention to learn: they have all chosen to study music and, in this, have already demonstrated a degree of internal motivation for learning music. However, it could also be used as a tool for pushing students beyond their comfortable pace of learning, to extend their achievement, and while a reward for a young student might be a physical object, for an 
advanced learner a reward could be their own recognition of mental achievement or of an opportunity gained because of their attainment.

It could be argued that keeping records of events and reviewing records of past performances have a less obvious connection with musical development than some of the other behaviors that received higher ratings. However, musicians can learn from listening to recordings, analyzing the content, and from noticing progress and recognizing areas needing further improvement. Learning also happens when a physical action is undertaken to reinforce learning, as when a teacher will notate something on the music or keeps a record of musical assignments will be kept in a notebook. This is a tool commonly used with younger students, partly as a method of communication with parents or others who might assist with practicing. The act of notating the content, purpose, and meaning of either physical or mental concepts that are introduced in a lesson or any intense rehearsal experience can serve to enhance learning, as the accuracy of only using memory to recall learned will diminish over time. It is possible that students do not realisz the value of this learning behavior or how it can be usefully applied to a musical setting.

The behavior involving the attention paid to selecting and arranging the practice environment was perceived as both one of the least necessary and most infrequently used strategies, although there is neither an obvious misfit between the questionnaire and practical learning in music nor is the application of this strategy in any way coded or hidden. Physical conditions such as having adequate light, a stand at the correct height, an appropriate chair and space all have an impact on a musician's health. The importance of this behavior is reinforced with the number of musicians who suffer from pain during their careers (Zara, 1998). The insight into what these music students considered important for musicians raised concern. Students may regard this as less important, as these results indicated, because they think health risks will not affect them or they might be ignorant of these issues. The place where students practice may be a fixed space provided for them where they study, and few have the luxury of planning a dedicated practice space. Those with large instruments such as the piano may not have an option to rearrange the position of their instrument, however small details involving the brightness of light or the height and angle of a chair can have a lasting effect to prevent physical damage or mental strain while playing.

Musicians are known to spend hours in the practice room, but even at this level the commitment of time does not guarantee that it is well spent, mentally or physically. When examining children's musical practice habits, McPherson and Renwick (2001) commented on both the appropriateness of the room chosen for practice and on the poor posture of students. This is not to say that at conservatoire or university level students replicate this behavior, but it does raise questions as to how students are instructed and when they learn these behaviors. As students in their first years of learning do not frequently use these strategies (McPherson \& Renwick, 2001), and the advanced students in the present research also believe them to be less important, this suggests that there is a need to educate musicians and reform their habits. Even at the fairly advanced levels of study found within higher education, students may not be making the best use of their time. Musicians may have the luxury of more time to devote to practice, as students, than when financial pressures mount after leaving education. Professional musicians may require a variety of well developed skills from sight reading or improvising in recording sessions, perform both solo and in groups, and the array of skills required to teach different students (Mills, 2004). Developing self-regulatory skills will enable these students to utilize their skills for more efficient and effective learning.

The results of this study highlight the importance of self-regulation and an awareness of methods for its implementation. The positive correlations shown between self-efficacy beliefs, skills, and self-regulated learning behaviors illustrate that these musicians engage with similar processes to those seen in other research with those learning in a classroom setting (Zimmerman \& Martinez-Pons, 1988; Risemberg \& Zimmerman, 1992; Zimmerman, 1998).

\subsection{Conclusions}

At advanced levels, teachers have been cited as advocating and demonstrating self-regulated learning behaviors to their students, and there is an awareness of the need to mix technical and musical and to cater to individual student's needs (Hallam, 1998, 2001b; Wilson, 2008). To facilitate learning, the performer-teacher Rostropovich taught his students methods for rearranging material to overcome the technical challenges of the instrument (Wilson, 2008), and one of the more creative of these was to ask his students to perform challenging passages from their repertoire in various keys. The level and style of input between teachers will vary and as students become more advanced, there may be greater expectations for the student to self-direct learning between lessons. Professionals also adopt a wide variety of approaches to address technical issues ranging from using dedicated studies to approaching difficulties through repertoire (Hallam, 1995). The students examined in the present study 
have already accumulated a good level of musical information and expertise, and they are at a point in their learning where they need to be able to assess and adopt relevant strategies for their learning.

Teachers hold a privileged role in disseminating knowledge and guiding students' learning, and they can utilize different self-regulated learning behaviors and strategies in teaching as well as make a concerted effort to convey the mechanisms of the processes to students. A hierarchical approach that includes goals and structured analytic thinking should make the long hours associated with expertise purposeful, and thus more productive (Ericsson et al., 1993). With awareness students can choose to use a given method, but if knowledge does not exist it is not realistic to expect students either to realize the value or to exhibit self-regulated learning behaviors in their learning. The qualities of the self-efficacious person are valued and should be apparent in musicians who utilize high levels of self-regulated learning. The behavior involving seeking advice from others is central to learning music, as students have regular contact with a teacher during lessons. It is important for music students and their teachers to be aware of how they spend their time developing and refining their musical skills. Understanding how these student musicians conceive of and approach their learning is a first step to having a strategic approach for learning and research, providing an alternative to focusing on the use of willpower to overcome obstacles to achieve their goals (Thoreson \& Mahoney, 1974). These skills will become markedly more essential as these students leave higher education and continue their musical careers, without the regular guidance and input from teachers (Hallam, 1995). Exploring self-regulated learning behaviors provides insight into the interaction of these unseen, personal self-beliefs and practical behaviors. Embedding and developing self-regulatory skills while the musicians are still in the formal education system can only equip developing musicians with a wider palate of self-reliance and autonomous learning to enable a successful transition into the professional world.

\section{References}

Bandura A. (1977). Self-efficacy: Toward a unifying theory of behavioral change. Psychological Review, 84, 191-215. http://dx.doi.org/10.1037/0033-295X.84.2.191

Barry, N. (1992). The effects of practice strategies, individual differences in cognitive style, and gender upon technical accuracy and musicality of student instrumental performance. Psychology of Music, 20, 112-123. http://dx.doi.org/10.1177/0305735692202002

Barry, N., \& Hallam, S. (1992). Practice. In R. Parncutt and G.E. McPherson (Eds.) Science and Psychology of Music Performance. (pp. 151-166). Oxford University Press, London.

Clark, T., \& Williamon, A. (2011), Evaluation of a mental skills training program for musicians, Journal of Applied Sport Psychology, 23, 342-359. http://dx.doi.org/10.1080/10413200.2011.574676

Cronbach, L. (1951). Coefficient alpha and the internal structure of tests. Psychometrika, 16(3), 297-334.

Ericsson, K., Krampe, R., \& Tesch-Römer, C. (1993). The role of deliberate practice in the acquisition of expert performance. Psychological Review, 100, 363-406. http://dx.doi.org/10/1037/0033-295X.100.3.363

Field, A. (2005). Discovering Statistics using SPSS, London, Sage.

Guadagnoli, E., \& Velicer, W. (1988). Relation of sample size to the stability of component patterns. Psychological Bulletin, 103, 265-275. http://dx.doi.org/10.1037/0033-2909.103.2.265

Hallam, S. (1995). Professional musicians' orientations to practice: Implications for teaching. British Journal of Music Education, 12, 3-19. http://dx.doi.org/10.1017/S0265051700002357

Hallam, S. (1997). The development of memorisation strategies on musicians: Implications for instrumental teaching. British Journal of Music Education, 14, 87-97. http://dx.doi.org/10.1017/S0265051700003466

Hallam, S. (1998). Instrumental teaching: A practical guide to better teaching and learning. Heinemann, Oxford.

Hallam, S. (2001a). The development of expertise in young musicians: Strategy use, knowledge acquisition and individual diversity. Music Education Research, 3, 7-23. http://dx.doi.org/10.1080/14613800020029914

Hallam, S. (2001b). The development of metacognition in musicians: Implications for education. British Journal of Music Education, 18, 27-39. http://dx.doi.org/10.1017/S02650517010000122

Jørgensen, H. (2004). Strategies for individual practice. In A. Williamon (Ed.) Musical Excellence. (pp.85-104). Oxford University Press, Oxford.

Kaiser, H. (1960). The application of electronic computers to factor analysis, Educational and Psychological Measurement, 20, 141-151. http://dx.doi.org/10.1177/001316446002000116

McPherson, G. E., \& McCormick, J. (2006). Self-efficacy and performing music, Psychology of Music, 34, 


\section{1-336. http://dx.doi.org/10.1177/0305735606064841}

McPherson, G. E., \& Renwick, J. (2001). A longitudinal study of self-regulation in children's music practice. Music Education Research, 3, 169-186. http://dx.doi.org/10.1080/14613800120089232

McPherson, G. E., \& Renwick, J. (2011). Self-regulation and mastery of musical skills. In B.J. Zimmerman \& D.H. Schunk (Eds.) Handbook of self-regulation of learning and performance (pp. 234-248). New York: Routledge.

Miklaszewski, K. (1989). A case study of a pianist preparing a musical performance. Psychology of Music, 17, 95-109. http://dx.doi.org/10.1177/0305735689172001

Mills, J. (2004). Working in music: Becoming a performer- teacher, Music Education Research, 6, 245-261. http://dx.doi.org/10.1080/1461380042000281712

Nielsen, S. (1999a). Learning strategies in instrumental music practice. British Journal of Music Education, 16, 275-291.

Nielsen, S. (1999b). Regulation of learning strategies during practice: A case study of a single church organ student preparing a particular work for a concert performance. Psychology of Music, 27, 218-220. http://dx.doi.org/10.1177/0305735699272015

Nielsen, S. (2001). Self-regulated learning strategies in instrumental music practice. Music Education Research, 3, 155-167. http://dx.doi.org/10.1080/14613800120089223

Nielsen, S. (2004). Strategies and self-efficacy beliefs in instrumental and vocal individual practice: A study of students in higher music education, Psychology of Music, 32, 418-431. http://dx.doi.org/10.1177/0305735604046099

Nunnally, J. (1978). Psychometric Theory (2 ${ }^{\text {nd }}$ ed.). McGraw Hill, New York.

Renwick, J., \& McPherson, G. E. (2009). Multiple motives: Profiles of young Australians' reasons for musical engagement. In A. Pretty \& R. Buck (Eds.), Proceedings of the International Symposium on Performance Science (pp. 469-474). Utrecht, The Netherlands: AEC.

Ritchie, L., \& Williamon, A. (2011) Measuring distinct types of musical self-efficacy. Psychology of Music, 39, 328-344. http://dx.doi.org/10.1177/0305735610374895

Risemberg, R., \& Zimmerman, B. (1992). Self-regulated learning in gifted students. Roper Review, 15, 98-101. http://dx.doi.org/10.1080/02783199209553476

Stewart, D. (1981). The application and misapplication of factor analysis in marketing research. Journal of Marketing Research, 18, 207-214.

Thoreson, C., \& Mahoney, M. (1974). Behavioural self-control. Holt, Rinehart, \& Winston, New York.

Williamon, A., \& Valentine, E. (2000). Quantity and quality of musical practice as predictors of performance quality. British Journal of Psychology, 91, 353-376. http://dx.doi.org/10.1348/000712600161871

Wilson, E. (2008). Mstislav Rostropovich: Cellist, teacher, legend. Faber, London.

Zara, C. (1998). Playing-related musculoskeletal disorders in musicians: a systematic review of incidence and prevalence. Canadian Medical Association Journal, 158, 1019-1025.

Zimmerman, B. (2002). Becoming a self-regulated learner: An overview. Theory into Practice, 41, 64-70. http://dx.doi.org/10.1207/s15430421tip4102_2

Zimmerman, B., \& Martinez-Pons, M. (1988). Construct validation of a strategy model of student self-regulated learning. Journal of Educational Psychology, 80, 284-290. http://dx.doi.org/10.1037/0022-0663.80.3.284

Zimmerman, B., \& Martinez-Pons, M. (1990). Student differences in self-regulated learning: Relating grade, sex, and giftedness to self-efficacy and strategy use. Journal of Educational Psychology, 82, 51-59. http://dx.doi.org/10.1037/0022-0663.82.1.51

Zimmerman, B., Bandura, A., \& Martinez-Pons, M. (1992). Self-motivation for academic achievement: The role of self-efficacy and personal goal setting. American Educational Research Journal, 29, 663-676. http://dx.doi.org/10.3102/00028312029003663 


\section{Appendix}

Musical Self-Regulated Learning Questionnaire

Name:

Date:

When practising or learning music, how often do you:

\begin{tabular}{|c|c|c|c|c|c|c|c|}
\hline \multicolumn{7}{|c|}{ Not at all } & Always \\
\hline Evaluate the quality or progress of learning. & 1 & 2 & 3 & 4 & 5 & 6 & 7 \\
\hline $\begin{array}{l}\text { Rearrange materials to improve learning } \\
\text { (changing the order of passages within a piece or } \\
\text { the inclusion of studies or other related musical } \\
\text { material). }\end{array}$ & 1 & 2 & 3 & 4 & 5 & 6 & 7 \\
\hline $\begin{array}{l}\text { Set goals and plan for the sequencing, timing, } \\
\text { and completion of activities in relation to those } \\
\text { goals. }\end{array}$ & 1 & 2 & 3 & 4 & 5 & 6 & 7 \\
\hline $\begin{array}{l}\text { Seek information from non-social sources } \\
\text { (recordings, concerts, books or scores). }\end{array}$ & 1 & 2 & 3 & 4 & 5 & 6 & 7 \\
\hline Keep records of events or results. & 1 & 2 & 3 & 4 & 5 & 6 & 7 \\
\hline $\begin{array}{l}\text { Select and rearrange the physical setting } \\
\text { (practice environment) to facilitate learning. }\end{array}$ & 1 & 2 & 3 & 4 & 5 & 6 & 7 \\
\hline $\begin{array}{l}\text { Arrange or imagine a reward/punishment for } \\
\text { success/failure. }\end{array}$ & 1 & 2 & 3 & 4 & 5 & 6 & 7 \\
\hline $\begin{array}{l}\text { Rehearse and make an effort to memorise } \\
\text { through practice. }\end{array}$ & 1 & 2 & 3 & 4 & 5 & 6 & 7 \\
\hline Seek assistance from peers, teachers or others. & 1 & 2 & 3 & 4 & 5 & 6 & 7 \\
\hline $\begin{array}{l}\text { Review records of past performances or exams, } \\
\text { notes or texts. }\end{array}$ & 1 & 2 & 3 & 4 & 5 & 6 & 7 \\
\hline
\end{tabular}

\section{(cc) EY}

This work is licensed under a Creative Commons Attribution 3.0 License. 